\title{
Proposed method for Analyze the QR code and Detection of Vulnerabilities
}

\author{
Sarah Saadoon Jasim \\ Middle Technical University \\ Computer Science/Technical college of \\ Management - Baghdad/Dept. of IT
}

Recived : 18\12\2017

Revised : //

Accepted : 27\12\2017

Available online : 26/1/2018

DOI: 10.29304/jqcm.2018.10.1.355

\begin{abstract}
A 2D matrix that is designed via keeping two points under consideration is QR code, in other words, it stores a large amount of data as compared to 1D barcodes. A Denso-Wave Corporation in Japan has been developed the QR code; the various marker of QR codes over traditional barcodes owns a large storage capacity, read faster, 360-degree reading, printing of small size, correction of error, and supports more languages. The use of QR codes has been expanding over the world because of these benefits. This paper tries to highlight the characteristics, working, significance, and vulnerabilities of the QR codes. After applying the proposed method, the irrelevant positions were detected, then it was removed without any effect on the QR code reading, and these positions are used to hide text or image; indicating that the proposed new method has shown some important characteristics which will affect the security and confidentiality of the QR-code.
\end{abstract}

Keywords: QR Code, Irrelevant positions. 


\section{Introduction}

In 1994 one of the Japanese Toyota group companies has created a QR code; QR code (Quick Response code) is a two-dimensional barcode [1]. In both the vertical and horizontal direction information is encoded, thus controlling up to several hundred times thus storing more data than a traditional barcode; using a camera to the access the data is by taking an image of the code (e.g. built into a smartphone) and this image is processing by a $\mathrm{QR}$ reader [2]. The function of symbols is similar to conventional barcodes; however, there is an ability to store additional data inside it. Criteria of forty versions have been defined on the different space of QR code [1]. In June 2000 propagated an international standard ISO/IEC 18004, has been focused on QR codes. QR codes are used firstly in the application of production control of automotive parts and since their development, in a lot of usages, a wide range is found in different regions. Generally, QR codes have been spread widely on declarations, products, and posters. In 2010, the International Air Transport Association (IATA) for worldwide airports integrated the QR code into passenger boarding passes. In hospitals were used QR code used especially for patient identification in Hong Kong. Another example of QR code was applied to the trains for ticketing system and airlines or to the bills for e-payment [3].

Recently, the QR code becomes extremely popular in digital image watermarking which can be used as a cover image or as a watermark. In our work, we focus on using the QR code as a cover image for hiding the information [4].

\section{Literature review}

Priyanka Gaur, Shamik Tiwari (2014) presents a novel method for QR barcode recognition using the texture features and neural network. All the operations are performed on the MATLAB platform. Performance of proposed methodology is evaluated using a database of QR code images. ZXing library is also used for recognition purpose, which shows the satisfactory results. Zxing library can decode all of them correctly. For the images with blur $86.66 \%$ recognition rate is achieved. The recorded recognition rate for the detected deformed barcode images is $70 \%$ [5].

D. Antony Praveen Kumar and M. Baskaran. (2016) Present the process is improving the steganography method using QR-code data input pattern image and LSB technique in RGB image. So, the proposed system process has done the message transferring effectively in a secure manner based on Least Significance Bit method and QR code pattern image. Finally, the resulted work is to increase the system performance level compare to existing methodology [6].

The Authors in Ref [7] analyze the QR codes based on their significance and use. They discuss the work of $\mathrm{QR}$ codes such that making the reader familiar with the QR codes; such that a many complex information can be stored in this small area. With increased awareness about the utility of these codes, we can look forward to using them in more general areas. 
In the work [8], an information form was used that combines cryptography and steganography; such that QR codes are applied to encode the message encrypted. The steganography of a nested image with the QR codes is been performed on an appropriate cover image and it is clear from the results that the Stego image was created a similar to the cover image, and these images cannot be identified by the eye of a human. From the selected images are proved MSE (mean square error) and RMSE (root means the error box) values.

\section{Quick Response code (QR code)}

QR code called matrix code and its a twodimensional encoding of data. This automatically readable matrix code consists of two boxes (black and white). It has been storing the data as a form of contact information, Uniform Resource Locator (URL), links to images or videos, clear text, and etc. [9].

\subsection{The architecture of QR Code:}

Each QR code is similar to the square models. the square of models divided into the two parts: area of encoding and models functions. Function models concentrate on positions that represent data encoding in a cryptographic region.

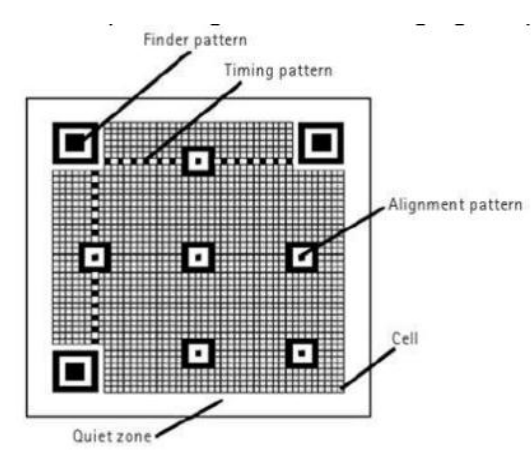

Fig (1) Architectural QR-code
In Figure (1) illustrates the QR code structure. patterns of the function include (finder, timing, and alignment) models. A finder patterns are three major structures based on three corners in the QRcode; for determining the correct orientation of a symbol uses Finder models. To detect the side of the pattern by a decoder software are used Timing models. In the case of an image, distortion uses the Alignment models to decode correctly a symbol via software decoder. The remainder of the area, which is not the function pattern; it is the encrypted area which the data codewords are stored and errors are corrected in code words [9]. The Quiet Zone is spacing area and its importance of the scanning program to differentiate between the QR code and surrounding of it's.

\subsection{Qualities of QR Code:}

The following some general qualities or characteristics in the $\mathrm{QR}$ code that must be identified:

a) Large space of storage: the QR code could be stored approximately 7,089 characters of data and where this size of data is huge compared with a $1 \mathrm{D}$ barcode.

b) Encryption a set of characters for the data:

- The data of numeric or the digits from 0 to 9 .

- The digits from 0 to 9; The letters from A to $\mathrm{Z}$ (upper case); other characters (space, :, \%, *, +, -, /,_, \$) or called data of alphanumeric.

- Characters of Kanji. 
c) Small Size for print: one of the characteristics of $\mathrm{QR}$ codes in the horizontal and vertical directions is storing the information, and depending on this characteristic with the same size of data, the space obtained via $\mathrm{QR}$ code is one to four times less than space obtained via One-dimensional barcode.

d) The Degree reading of the QR code is 360: from the characteristics of the QR code is reading from any direction; and it was applied by the finder samples found at three corners of the code. These samples help to determine characteristics of $\mathrm{QR}$ code.

e) Correction of error and ability of the restoring: data can be retrieved in case if part of the code is been harming or contaminated; the procedure of error detection can be centralizing on the correct data area; L, M, Q and $\mathrm{H}$ are four levels of QR code of error correction. The weakest in level $\mathrm{L}$ and the strongest in level $\mathrm{H}$ such as the error correction capability [10].

\section{Uses and importance of $Q R$ code:}

The QR code readers provide a straightforward representation with an appropriate access to data. Therefore, the QR codes are used widely for the declaration of products, links to companies' website, and competition for sign up pages. The printing of QR code on the building may enable the guestor for knowing the building's history, and it might give data about its architect or about how to build the building. There are various ways to use the QR codes [9]: $\checkmark \quad$ In business company cards: QR code on the business cards is an excellent location. Meet someone at any pooling, get automatically on their communication data and saved on your smartphone by scanning a QR code.

$\checkmark$ Advertisements of the magazine: in any magazine, a product announcement in addition to the QR code might bring the attention of the reader to the site of the company; and the client might reading about this product and purchasing it.

$\checkmark$ Restaurants and Cafes: The prioritize client in the restaurants or any cafe shop offering a specific or free rebate in addition to a ready meal via the use of a QR code printed on their dining tables.

$\checkmark$ Manufacturers of equipment: we can add QR code to the instruction manual by the manufacturer of the product that transport people to electronic content and help use products.

$\checkmark \quad$ Talking Labels: If you print a QR code on your talk labels, the product poster becomes alive. A code may be taking the guestor to a video or may be shown images of interesting to the product that may affect buyers.

\section{Proposed Methodology}

The main objective of our proposed system is to discover the irrelevant positions that do not affect the QR code reading, and these positions are used to hide text or image. The work of a QR code involves two parts encoding and decoding of the data. The Fig (2) shows the schematic flow diagram of the proposed work. 


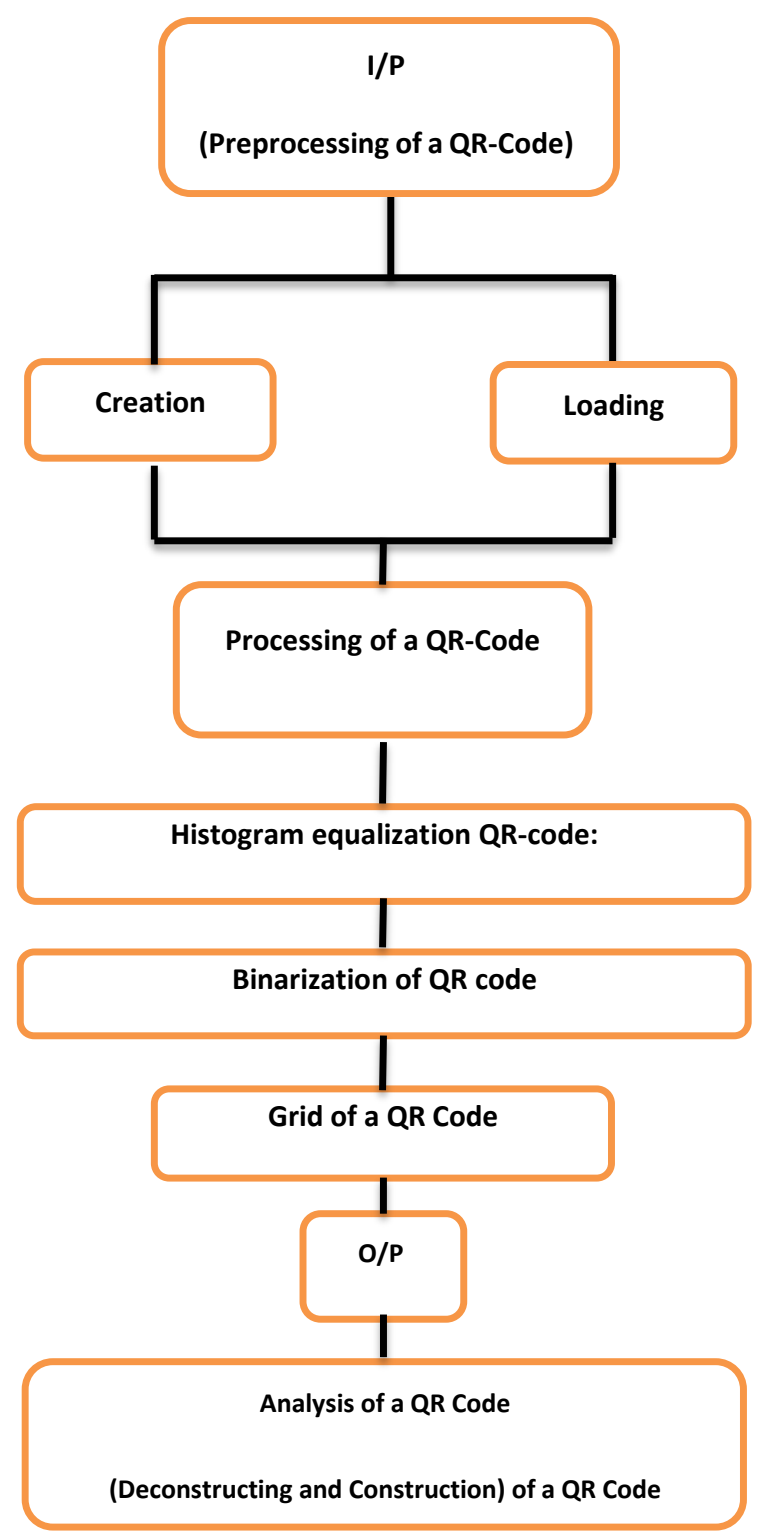

Fig (2) Block diagram of the proposed system

\subsection{Preprocessing of a QR Code}

At this stage, there is a set of pre-processes that should be taken into our consideration to create the $\mathrm{QR}$ code, and these pre-processes are presented as follows:

\section{A. QR-code Creation:}

In this process, load the image of QR code directly, or choosing a type of code that you want to create by entering the data to attach it to the symbol; then, click on button "Creating of QR Code". After that, QR code is generated in the program. Fig. 3 shows how a QR code can generate.

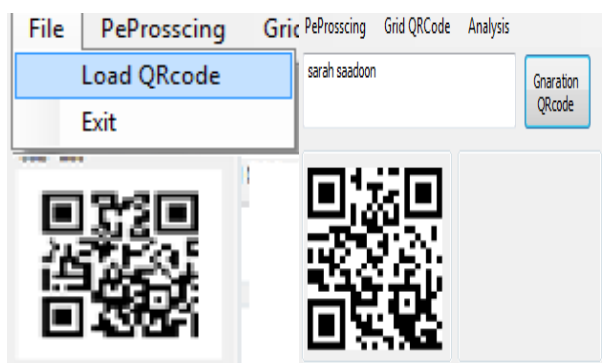

(a) Loading 'of QR'-Code (b) Creating of QR-Code

Fig (3) (Creating, Loading) QR Code

\section{B. QR-code Histogram equalization and Binarization:}

In the case of loading the image of $\mathrm{QR}$ code; the processes of histogram equalization and binarization are important to remove the existing noise in $\mathrm{QR}$ code image. The equalization of the histogram is a common technicality to improve the appearance of the poor image, a function similar to the histogram extension process and gives satisfactory results for images with a wide range of gray levels such that the Histogram Equalization is a technicality that makes the resulting image as simple as possible as flat. The theoretical basis of the histogram equalization is based on probability theory, where it is treated as a probability distribution of gray levels. The histogram equalization process consists of four steps (see Fig 4): 
- Find the Running Sum of the histogram values.

- Divide the resulting values from step (a) on the total number of image elements normalize.

- Multiply the values by step (b) with the value of the larger gray level and rotate the result to the nearest integer.

- Match the values of gray levels with the results of step (c).

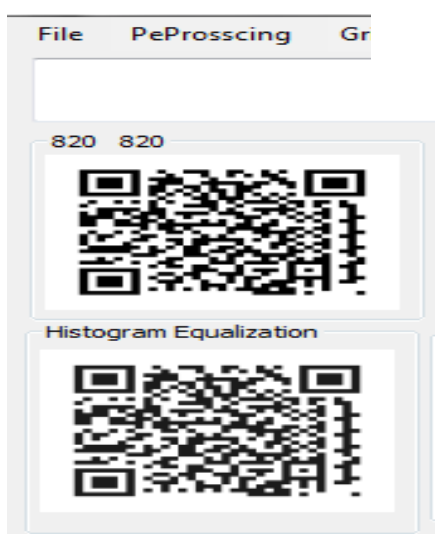

Fig (4) Histogram equalization QR-code

With the QR code binarization process, the images are converted to grayscale and converted to black and white (binary image) according to the value of threshold 130, as shown in Fig 5.

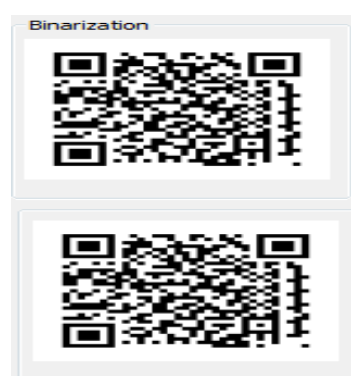

Fig (5) Binarization QR-code

\section{Grid of a QR Code}

This process explained the grid, height, and width of QR code for knowing the number of pixels and finding the positions that can be used for hiding the information; in addition to convert the $\mathrm{QR}$ code to the binary system. This process is represented in the following steps:

- Clip of a QR Code to delete the white areas surrounding the QR-code (as shown in Fig 6).

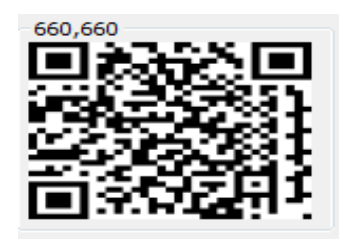

Fig (6) Clip QR-code

- $\quad$ Ridge of a QR Code: at this step, we find the width and the height of the QR-code; through which the QR-code is divided into a grid of white and the black boxes (see Fig 7). The Ridge of a QR Code is constructed by using Equation (1):

Ridge $Q R$-code $=$ width $*$ height

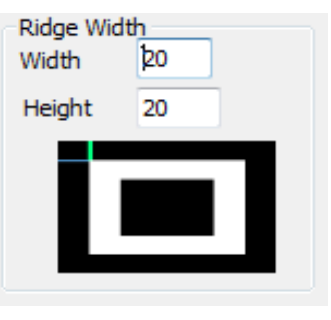

Fig (7) Ridge QR-code 
- Draw ridge of a QR Code: in this step, the pixels are drawn based on the previously computed grid to determine the number of positions (blocks) to be used for hiding information without any effecting on the QR code (see Fig 8).

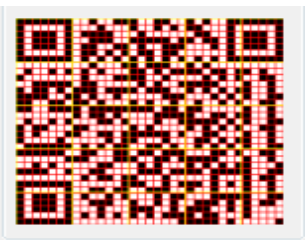

Fig (8) Draw ridge of QR-code

\subsection{Analysis of a QR Code}

The final process is done by firstly, deconstructing the QR Code and using a mask of (3 * 3) to take all the possible probabilities in QR code to find the number of positions for hiding information as represented in equation (2);

Number of hidden blocks $=$ Ridge $Q R$-code $*$ Number of blocks

Secondly, a construction of the QR Code is done (see Fig 9, 10).

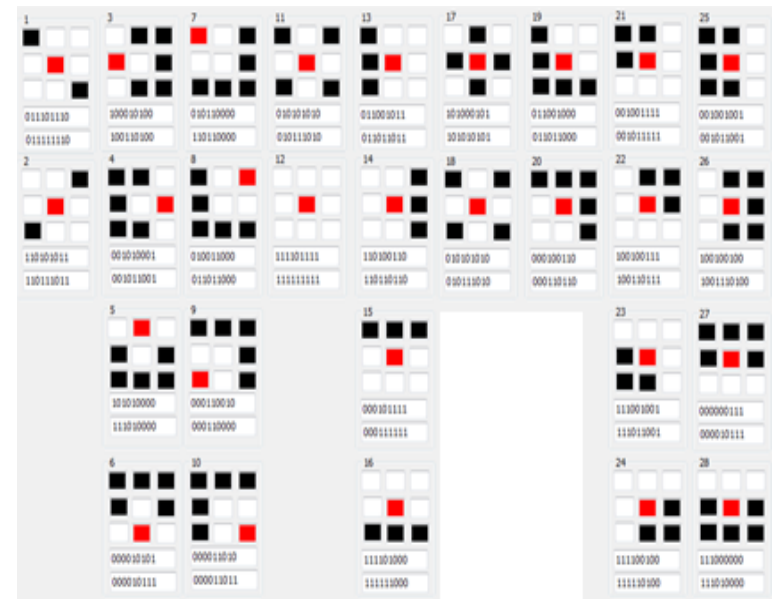

Fig (9) Finding the Number of hidden blocks in the

QR-code

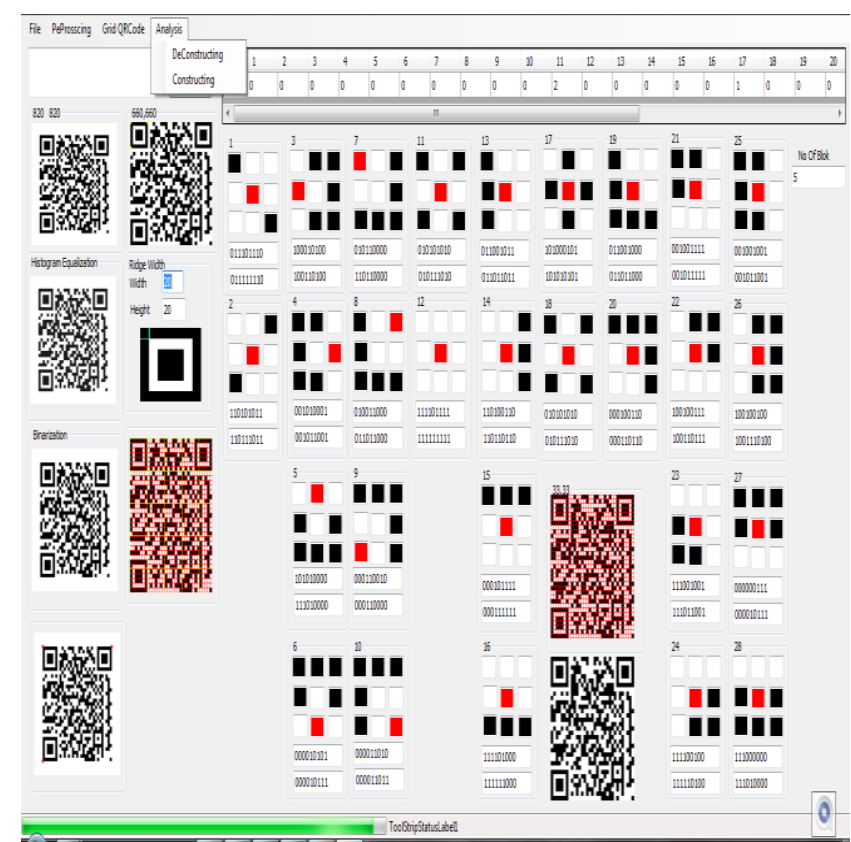

Fig (10) The overall proposed system

6. Experimental results

To evaluate the proposed system, a lot of loaded QR codes are used, and after applying our method, we can get the irrelevant positions as demonstrated in Table 1. And Table 2 shows the original QRcodes and the QR-codes without the irrelevant blocks. 
Journal of AL-Qadisiyah for computer science and mathematics $\quad$ Vol.10 No.1 Year 2018 ISSN (Print): 2074 - $0204 \quad$ ISSN (Online): 2521 - 3504

Sarah .S

Table (1) Show number of pixel of irrelevant blocks

\begin{tabular}{|c|c|c|}
\hline $\begin{array}{c}\text { Number of } \\
\text { bits }\end{array}$ & $\begin{array}{c}\text { Number of } \\
\text { blocks }\end{array}$ & $\begin{array}{c}\text { Number of hidden } \\
\text { blocks }\end{array}$ \\
\hline 32 & 9 & 576 \\
\hline 56 & 13 & 832 \\
\hline 88 & 8 & 512 \\
\hline 112 & 9 & 576 \\
\hline 120 & 13 & 5200 \\
\hline 272 & 16 & 6400 \\
\hline 352 & 13 & 5200 \\
\hline 616 & 30 & 12000 \\
\hline 704 & 39 & 15600 \\
\hline 1200 & 23 & 368 \\
\hline 3080 & 103 & 41200 \\
\hline
\end{tabular}

Table (2) Show original QR-code and QR-code after eliminating the irrelevant blocks

\begin{tabular}{|c|c|c|c|c|c|}
\hline \multirow{2}{*}{$\begin{array}{l}\text { Num } \\
\text { ber } \\
\text { of } \\
\text { bits }\end{array}$} & \multicolumn{3}{|c|}{ QR-code } & \multirow[b]{2}{*}{ Final QR-code } & \multirow{2}{*}{$\begin{array}{l}\text { (Pass/ } \\
\text { Not } \\
\text { Pass) } \\
\text { of } \\
\text { QR- } \\
\text { code }\end{array}$} \\
\hline & Original & $x$ & $y$ & & \\
\hline 32 & : & 200 & 200 & 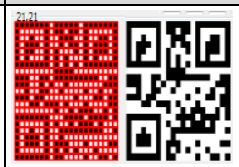 & Pass \\
\hline 56 & $\square$ & & & 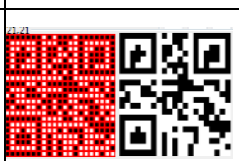 & Pass \\
\hline 88 & 口200 & 200 & 200 & 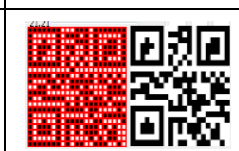 & Pass \\
\hline 112 & & & & 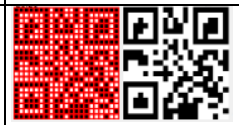 & Pass \\
\hline 120 & 回军回 & 660 & 660 & 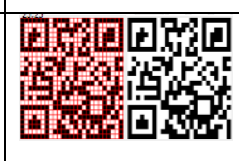 & Pass \\
\hline 272 & 回被回 & 820 & 820 & 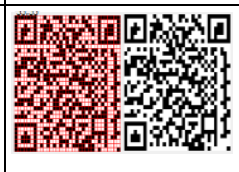 & Pass \\
\hline 352 & 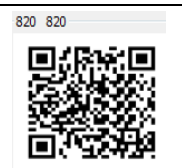 & 820 & 820 & 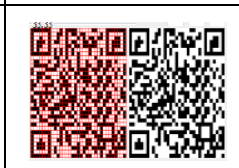 & Pass \\
\hline 616 & 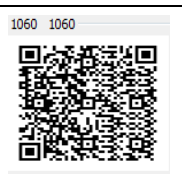 & 1060 & 1060 & 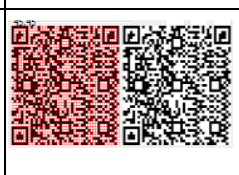 & Pass \\
\hline 704 & 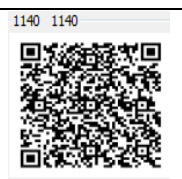 & 1140 & 1140 & 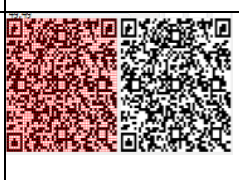 & Pass \\
\hline 1200 & 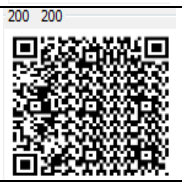 & 200 & 200 & 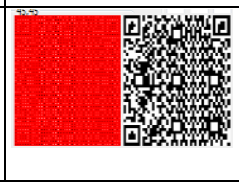 & Pass \\
\hline 3080 & 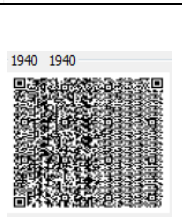 & 1940 & 1940 & 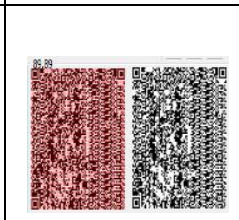 & $\begin{array}{l}\text { Not } \\
\text { Pass }\end{array}$ \\
\hline
\end{tabular}




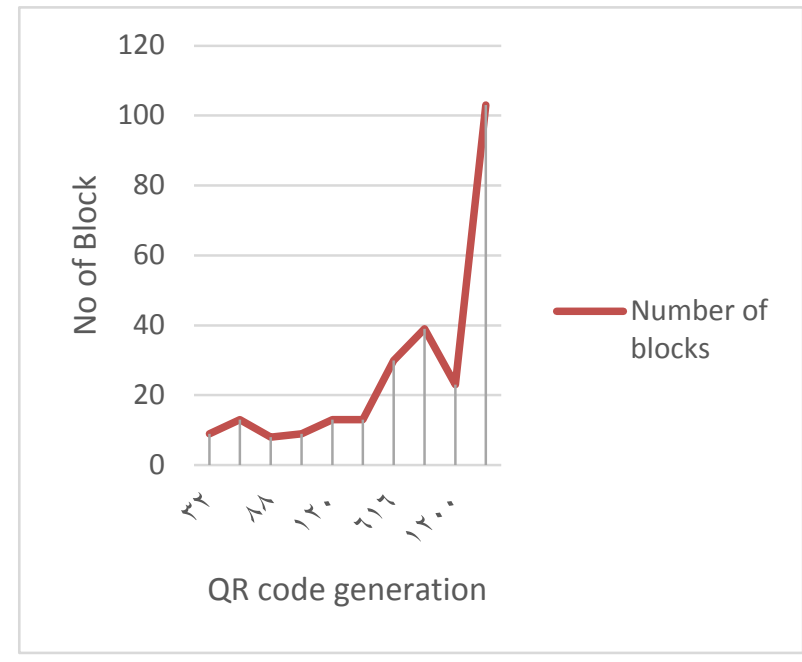

Fig (11) The number of blocks for the generated QR codes

The diagram above shows the number of blocks that have been changed (i.e. removed from the QR code) within a set of generated QR code. Which in turn did not affect the process of reading and retrieving information from the code through the scanner? So, this paper shows that there are a number of irrelevant blocks that can be used to hide the data without any effect in the process of retrieving $\mathrm{QR}$ code data.

\section{Conclusion}

In this paper, a set of unimportant points (irrelevant positions) was discovered in QR Codes; after removing it, QR codes will not be affected and still be readable normally. The removing of these irrelevant positions makes the proposed method faster in coding, discovery and reduce the size of the QR Codes.

\section{References}

[1] David Pintor Maestre, "QRP: An improved secure authentication method using QR codes", Universitat Oberta de Catalunya, 08018, Barcelona, Spain,dpintor@uoc.edu, June 8, 2012.

[2] Kieseberg P., Leithner M., Mulazzani M., Munroe L., Schrittwieser S., Sinha M., AND Weippl E., "QR Code Security', the $8^{\text {th }}$ International Conference on Advances in Mobile Computing and Multimedia, Paris, France November 08-10-2010, Pages 430-435. doi $>10.1145 / 1971519.1971593$.

[3] Falkner S., Kieseberg P., E. Simos D., Traxler C., and Weipp E., "E-voting Authentication with QR-codes”, International Conference on Human Aspects of Information Security, Privacy, and Trust HAS 2014: LNCS 8533, pp. 149-159, 2014. https://link.springer.com/chapter/10.1007/978-3319-07620-1_14.

[4] Jumana W., Dong Jun H., Sarah S., Saad H., and Hiyam H., “ An Immune Secret QR-Code Sharing based on a Twofold Zero Watermarking Scheme". International Journal of Multimedia and Ubiquitous Engineering Vol.10, No.4 (2015), pp.399-412. http://dx.doi.org/10.14257/ijmue.2015.10.4.38.

[5] Gaur P., Tiwari S., "2D QR Barcode Recognition Using Texture Features and Neural Network", International Journal of Research in Advent Technology, Vol.2, No.5, May 2014 EISSN: 2321-9637. 
[6] D. Antony Praveen K., and M. Baskaran, "Data Hiding Using LSB with QR Code Data Pattern Image", International Journal of Science Technology \& Engineering | Volume 2 | Issue 10 | April 2016 ISSN (online): 2349-784X.

[7] Kulkarni S. S.and Malagi C., "Creation and Analysis of QR Code", Bonfring International Journal of Software Engineering and Soft Computing, Vol. 6, Special Issue, October 2016.

[8] B Karthikeyan, Kosaraju C. A., Gupta S S., "Enhanced Security in Steganography using Encryption and Quick Response Code”, This full- text paper was peer-reviewed and accepted to be presented at the IEEE WiSPNET 2016 conference.

[9] Sangeeta Singh, "QR Code Analysis", International Journal of Advanced Research in Computer Science and Software Engineering, Volume 6, Issue 5, May 2016 ISSN: 2277 128X.

[10] International Standard ISO/IEC 18004, "Information technology Automatic identification and data capture techniques Bar code symbology QR Code", Reference number - ISO/IEC 18004:2000(E), First Edition 2000-06-15.

\section{الطريقة المقترحة لتحليل رمز الاستجابة السريعة والكشف عن مواطن الضعف}

رمز الاستجابة السريعة هي مصفوفة ذات بعدين التي تم تصميمها باعتبار ها اساسا نقطتين، وبعبارة أخرى، فإن رمز الاستجابة السريعة يخزن كمية كبيرة من البيانات بالمقارنة مع الباركود ذات البعد الواحد. وقد طورت شركة دينسو في اليابان رمز الاستجابة السريعة مقارنة مع الباركود التقليدية حيث تمتلك سعة تخزين كبيرة، قراءة أسرع، وقراءة . بس درجة، طباعة صغيرة الحجم، وتصحيح الاخطاء، ويدعم المزيد من اللغات. وبسبب هذه الفوائد تم التوسع في استخدام رمز الاستجابة السريعة في جميع أنحاء العالم ـ هذه البحث يحاول تسليط الضوء على خصائص، عمل، أهمية، ومواطن الضعف لرمز الاستجابة السريعة. بعد تطبيق الطريقة المقترحة، تم الكثف عن المواقع غير المهمة، ثم تمت إز التها دون أي تأثير على قراءة رمز الاستجابة السريعة، وتستخدم هذه المو اقع لإخفاء نص أو صورة. مشيرا إلى أن الطريقة الجديدة المقترحة أظهرت بعض الخصائص الهامة التي سوف تؤثر على أمن وسرية رمز الاستجابة السريعة.

كلمات البحث: رمز الاستجابة السريعة، والمواقع غير المهمة. 